\title{
PROBLEMAS EN EL USO DE LAS ANÁFORAS EN PRODUCCIONES ESCRITAS DE ESPAÑOL COMO LENGUA EXTRANJERA
}

\author{
Sergi Torner Castells \\ Carmen López Ferrero \\ ERnesto Martín Peris \\ Universitat Pompeu Fabra
}

\section{RESUMEN}

En este artículo se abordan los problemas que entraña el empleo de las formas anafóricas por parte de estudiantes avanzados de español como lengua extranjera (ELE). Con este fin, analizamos un corpus de textos escritos por estudiantes Erasmus, en el que describimos y explicamos todos los errores observados en el uso de las anáforas. Los resultados de nuestro estudio muestran que los mecanismos de referencia anafórica en español constituyen un procedimiento complejo, debido tanto a la variedad de formas lingüísticas que pueden desempeñar función anafórica como a los distintos campos de referencia a los que estas formas pueden remitir. En concreto, la elección de una forma anafórica debe atender a tres factores distintos: i) el tipo de contexto al que remite la anáfora y, por tanto, el tipo de señalamiento activado (textual o cognitivo), ii) el papel sintáctico-semántico que desempeña el elemento anafórico y iii) su función pragmática en la estructura informativa de la oración y del discurso (fundamentalmente, tema y foco o contraste). Las conclusiones de nuestro estudio tienen interés tanto descriptivo como didáctico: desde el punto de vista de la gramática descriptiva, ahondamos en la explicación de unos fenómenos lingüísticos complejos para los cuales las descripciones existentes no resultan plenamente satisfactorias; desde el punto de vista de la aplicación didáctica, identificamos algunos de los factores que se deben tener en cuenta en una gramática pedagógica del ELE. En este sentido, es de especial utilidad identificar el tipo de conocimiento necesario para gestionar la anáfora, así como también su papel en el desarrollo informativo del texto, en la sintaxis de la oración y en la estructura argumental del predicado.

Palabras clave: anáfora textual, deixis cognitiva, cotexto, contexto, elipsis, pronombre personal, pronombre demostrativo.

\section{ABSTRACT}

In this article we approach the difficulties that students at advanced levels of Spanish as a Foreign Language (the acronym of which in Spanish is ELE) have when using anaphoric forms. We analyse a corpus of written texts from Erasmus students in order to account for all the mistakes regarding the use of anaphora. Our results show that the use of anaphora in Spanish is quite complex, due both to the variety of 
linguistic forms that may be used and to the different fields of reference these forms may refer to. More specifically, when choosing one form of anaphora, one must take into consideration three different factors: i) the type of context the anaphora refers to and, therefore, the kind of activated signalling (either textual or cognitive); ii) the syntactic-semantic function performed by the anaphoric element and iii) its pragmatic value in the informative structure of the clause and of discourse (mainly, the topic, and the focus or contrast). The conclusions of our study have both a descriptive and a pedagogical value: from the point of view of descriptive grammar, we delve into the explanation of some complex linguistic phenomena the description of which is not yet entirely satisfactory; from the point of view of the pedagogical implementation, we identify some of the factors which should be taken into account in a pedagogical grammar of ELE. It is particularly useful to identify the kind of knowledge necessary to correctly produce anaphoric reference, as well as the role of this knowledge in the informative development of the text, in the syntactic structure of sentences and in the argument structure of verbs.

Key Words: textual anaphora, cognitive deixis, cotext, context, ellipsis, personal pronoun, demonstrative pronoun.

RECIBIDO: 18/06/2009

AProbado: 30/05/2010

\section{INTRODUCCIÓN: OBJETIVO DEL ESTUDIO Y METODOLOGÍA}

En la enseñanza del español como lengua extranjera (ELE), especialmente en los niveles superiores, pueden detectarse áreas de dificultad todavía no estudiadas en la producción de los estudiantes y, en consecuencia, tampoco suficientemente descritas por las gramáticas pedagógicas. Una de ellas es el uso de las anáforas, de especial dificultad para los hablantes no nativos dado que requiere manejar conocimientos tanto gramaticales como discursivos muy diversos. Como es sabido, la referencia anafórica es un fenómeno complejo que no solo afecta a elementos distintos del sistema de la lengua (pronombres personales, artículos y demostrativos, posesivos, locativos, proverbios, etc.), sino también a diversas funciones sintácticas (sujeto, complementos directo e indirecto, circunstanciales). En el caso del español, además, que es una lengua de sujeto nulo, se produce un contraste con otras lenguas que conocen los estudiantes en cuanto a la posibilidad de recuperar anafóricamente el sujeto de la oración con una forma expresa o bien mediante la elipsis.

El objetivo de este trabajo consiste en describir y explicar las dificultades que el empleo de las anáforas supone para los estudiantes de niveles superiores de ELE en sus composiciones escritas. Para alcanzarlo hemos analizado los textos producidos por un grupo de estudiantes que participaron en un intercambio Erasmus en nuestra universidad. Se trataba de estudiantes procedentes de facultades de Filología Hispá- 
nica, de Lenguas Aplicadas, de Traducción, etc. Al iniciar el curso en nuestra universidad, todos ellos habían tenido que hacer obligatoriamente una prueba de nivel, y estaban clasificados en el nivel superior entre los que se ofertan en el programa, equivalente aproximadamente a un B2 del Marco común europeo de referencia para las lenguas (2001); es decir, eran estudiantes que poseían una competencia alta en el uso del español, pero necesitaban reforzar su conocimiento de determinados recursos gramaticales y discursivos. En la clase de ELE que seguían estos alumnos se trabajaba intensamente la escritura, realizada a partir de la lectura o la audición de textos. Para el presente estudio, hemos seleccionado sendos escritos de cada estudiante correspondientes a los dos tipos de texto siguientes:

a) el relato en tiempo pasado de una anécdota previamente escuchada en su versión oral;

b) el comentario en futuro sobre el regreso a su país después del intercambio Erasmus.

Nuestro corpus de estudio comprende un total de 50 textos de entre 300 y 500 palabras cada uno.

En nuestro análisis de estos textos nos hemos centrado en los errores que presentan en el dominio de la anáfora; es decir, no consideramos los numerosos casos en que los estudiantes utilizan adecuadamente recursos anafóricos, por cuanto nos interesa describir aquellas áreas que entrañan dificultad para los aprendientes. Así pues, para llevar a cabo el análisis hemos detectado los errores debidos a un mal empleo de las referencias anafóricas, los hemos descrito y categorizado y, finalmente, hemos tratado de ofrecer una razón (gramatical, semántica, textual o cognitiva, o un conjunto de ellas) que diera cuenta de estos errores. En este sentido nuestro concepto de «error» sigue el trabajo ya clásico de Corder 1967 y la vinculación que en él se propone con el concepto de interlengua. Algunos gramáticos podrían no considerar erróneas muchas de las ocurrencias que estudiamos; sin embargo, la mayor parte de los hablantes de español se expresarían de otro modo y considerarían ajenas al uso de un nativo estas formas de expresión presentes en nuestros textos ${ }^{1}$. Debemos precisar, finalmente, que no ofrecemos un análisis cuantitativo ni una presentación exhaustiva de los problemas hallados, sino que destacamos los más representativos de los 50 textos analizados.

Una de las principales conclusiones que se desprende de nuestro estudio es que para un manejo apropiado de la anáfora en español se

\footnotetext{
1 En la bibliografía sobre adquisición de segundas lenguas se considera la «naturalidad en la expresión» como uno de los componentes de la competencia comunicativa (cf. Bachman 1990, p. 97).
} 
requiere tener en cuenta factores sintácticos, semánticos, textuales y cognitivos complejos: es necesario no solo disponer del paradigma de formas lingüísticas con función anafórica y conocer sus posibilidades sintácticas, sino también entender cómo funciona la referencia anafórica a nivel textual (en el desarrollo informativo del discurso) y conocer cómo cada lengua categoriza conceptualmente la realidad referida a través de la anáfora. En definitiva, explicar la anáfora implica abordar cuestiones de gramática en relación con las formas lingüísticas y sus funciones (sintácticas y semánticas), y comprender cuestiones de lingüística textual y cognitiva en relación con los tipos de anáfora posibles y con las funciones informativas y cognitivas que la anáfora pone de relieve (tema y rema, foco o contraste, fondo y figura). Son estas las cuestiones que planteamos brevemente en el siguiente apartado, como marco conceptual para explicar los problemas identificados.

\section{TIPOS DE ANÁFORA: GRAMÁTICA, TEXTO Y COGNICIÓN}

Para una adecuada comprensión de los problemas analizados se requiere considerar previamente los diferentes procedimientos de anáfora existentes en español. Esbozamos por ello una tipología de la anáfora -de carácter provisional y operativo- en la que introducimos conceptos que más tarde usaremos en el análisis.

No todos los autores que se han ocupado de la anáfora utilizan los mismos términos para referirse a los mismos fenómenos. Nosotros adoptamos en este estudio una conceptualización teórica que -tanto para el tema de la anáfora como para el más general de la deixis- puede establecerse a partir de la teoría del lenguaje de Bühler 1934, la teoría de la enunciación de Benveniste 1974 y los planteamientos que sobre la cohesión textual han realizado Halliday y Hasan 1976 en el marco de la gramática funcional.

Tratamos únicamente errores en el uso de la anáfora y prescindimos de los problemas de referencia exofórica (o deixis en sentido estricto), que solo tomamos en consideración en tanto en cuanto su dominio por parte de los estudiantes interfiere con el de la anáfora. Desde un punto de vista conceptual, la diferencia entre anáfora y deixis parece clara: la anáfora es un mecanismo lingüístico de señalamiento mediante el cual un elemento de un texto adquiere su referencia por alusión a otro elemento que está presente en el discurso enunciado; se trata, por lo tanto, de una referencia «endofórica» o «intratextual», frente a la deixis, definida como referencia «exofórica» o «extratextual». A la primera se la denomina también «lineal» y a la segunda, en palabras de Bühler 1934, pp. 124 y ss., «ad oculos» (o «sensible»). La diferencia fundamental entre estos dos tipos de referencia es, pues, el contexto al que remiten: la 
anáfora remite a elementos del contexto lingüístico o cotexto (Halliday y Hasan 1976, pp. 32 y ss.); la deixis señala elementos del contexto empírico (en términos de Coseriu 1962, p. 315). Sin embargo, la mayor parte de los autores reconoce que los límites entre anáfora y deixis no son nítidos (cf. Mederos 1988, Moreno Cabrera 2000, Cifuentes Honrubia 1989, Vicente Mateu 1994).

En este sentido, Fernández Ramírez 1985-1987, p. 129, afirma que «en la mención a lo ya dicho o escrito hay como un movimiento vacilante y pendular que va del campo textual al mundo objetivo». Por ello, siguiendo a este autor se puede considerar un tercer campo de referencia, imbricado con los dos anteriores, constituido por el contexto cognitivo (Schank y Abelson 1977, Van Dijk 1977, Sperber y Wilson 1986); este contexto comprende todos los conocimientos que los interlocutores presuponen compartidos, y que pueden haber sido originados en el desarrollo del propio discurso o bien con anterioridad a su inicio. Distinguimos así cuatro tipos de referencia (soslayando de modo consciente la discusión sobre la naturaleza deíctica o anafórica de los mismos):

i. Al contexto empírico de la situación de comunicación: «deixis exofórica».

ii. A la materialidad lingüística del texto: «deixis textual» (Fernández Ramírez 1987, p. 129; Conca y otros 1998, pp. 139-140; Eguren 1999, pp. 966-967); se trata de una deixis o una mostración al texto en cuanto producto y pertenece a la esfera de lo metalingüístico (Esta frase no tiene sentido. ¿Puedes repetir eso?).

iii. Al contenido del discurso, al cotexto: «anáfora textual».

iv. Al contexto cognitivo, a conocimientos que el emisor asume como compartidos con el destinatario: «deixis cognitiva».

Constituyen objeto de nuestra atención únicamente los dos últimos, la «anáfora textual» y la «deixis cognitiva», a cuya sucinta presentación dedicamos las páginas que siguen.

\subsection{Anáfora textual}

Una anáfora textual refiere al contenido proposicional de un fragmento discursivo anterior (una palabra, una frase o un segmento más extenso); es, por tanto, un procedimiento que toma como campo de referencia el contexto lingüístico o cotexto.

Este tipo de referencia endofórica puede realizarse mediante una forma expresa (en adelante, «anáfora expresa») o por medio de la elipsis (en adelante, «anáfora por elipsis»). La elección entre una y otra supone una adecuada gestión de la información en el discurso, en concreto de la progresión temática. Cuando hay cambio de tema oracional o contraste, la estructura informativa impide la elisión del sujeto o de 
los complementos que son tema y exige la presencia de una anáfora expresa que permita identificar inequívocamente el referente. La elipsis se da, pues, cuando se mantiene en la oración el tema del discurso.

La anáfora textual expresa puede servirse de procedimientos diversos: la repetición (léxica, de un $\mathrm{SN}$, de una frase u oración, de un fragmento textual más extenso), la sustitución léxica (mediante sinónimos, hiperónimos, paráfrasis) o el empleo de proformas -pronombres (personales, demostrativos, indefinidos), proformas léxicas (nombres), proverbos, proadverbios-. En los casos de repetición y de sustitución de sustantivos, debe elegirse, además, el determinante que actualiza el nombre: artículo, posesivo, indefinidos -como tal, otro, mismo- o demostrativos (con sus diversas formas), que, a su vez, pueden adoptar matices diferentes si van en sustitución del nombre, o bien acompañándolo antepuestos o pospuestos.

Según el valor referencial que tiene la forma anafórica, se pueden distinguir dos tipos distintos de anáfora textual:

a) «Anáfora correferencial»: el elemento anafórico y el referente remiten a una misma realidad extralingüística. Así, en (1) María y le son elementos correferenciales:

(1) He hablado con María, pero no le he dicho que venga.

En relación con este tipo de anáfora, Fernández Ramírez 1987, pp. 115-126, señala la existencia de una «anáfora difusa», consistente en la elaboración de un nuevo concepto que recoge lo anteriormente dicho, como ilustra (2), ejemplo que aporta este autor:

(2) No he bailado porque a Julianita nadie le decía nada, y como se muere de envidia, no he querido darle ese mal rato (Jacinto Benavente).

b) «Anáfora de sentido»: el elemento anafórico y el referente presentan el mismo sentido, aunque no son correferenciales, tal como ilustra (3), donde libro y otro remiten a dos referentes distintos de la misma clase.

(3) Coge tú este libro; yo me llevaré otro.

\subsection{Deixis cognitiva}

La deixis cognitiva es un tipo de referencia discursiva mediante el cual el emisor evoca unos conocimientos que asume como compartidos con el destinatario (de ahí que Fernández Ramírez 1987, pp. 119122, la designe también con el nombre de «mención evocativa»). Con la deixis cognitiva, el emisor remite al contexto cognitivo, en particular a 
un espacio-mundo que ha creado con sus palabras o bien que activa a partir de conocimiento enciclopédico, y lo presenta como ya externo al discurso, con autonomía propia. Este contexto se constituye así en parte de la enunciación, como un espacio nuevo que se añade al espacio real.

Señala Fernández Ramírez 1987 que esa anáfora evocativa puede cumplir dos funciones. Por un lado, una función tipificadora -ilustrada en (4)-, con la que se crea un determinado tipo en el que incluir la entidad a la que se hace referencia. Por otro, una función singularizadora -ilustrada en (5)-, que supone una elaboración conceptual en la que el pronombre apunta al esquema del concepto que va a formarse:

(4) Un barrio de esos que imaginas.

(5) Pero lo que más le intrigaban eran los viejos, esos viejos de París de cara surcada y marchita (Baroja).

Según la mayor parte de los autores consultados, para la deixis cognitiva el español recurre preferentemente al SN con demostrativos, con artículo o con posesivo. Entre estos tres recursos, el más frecuente es el uso del demostrativo, por la propiedad señaladora o discriminante que tiene frente al artículo y que permite hacer una indicación de proximidad/lejanía en el tiempo o en el espacio, además de otro tipo de referencia deíctica (personal, social...); a este respecto Eguren 1999, p. 935, distingue la deixis emocional o empatética:

Las relaciones (primarias) de proximidad relativa de los demostrativos este, ese, aquel con respecto al centro deíctico pueden verse alteradas como consecuencia del grado de implicación emocional o de las actitudes del hablante, con respecto a su interlocutor o a algún otro elemento del contexto de enunciación.

Cuando se recurre a los demostrativos, en la mención evocativa no aparece nunca el de $1 .^{a}$ persona y es más frecuente el de $2 .^{a}$ que el de 3..$^{\text {a }}$ que se usa para señalar lejanía en el tiempo o en el espacio. La carga empatética que uno y otro (indistintamente) pueden cobrar adoptará valores positivos o negativos en función de otros índices presentes en el contexto cognitivo.

Los conceptos aquí sucintamente esbozados permiten analizar los errores de los estudiantes que documentamos en nuestro corpus. En las páginas que siguen presentamos nuestro análisis, que estructuramos en tres grandes secciones, correspondientes a los tres grandes ámbitos en los que se concentran los errores de los estudiantes. Los dos primeros reúnen problemas en la elección del procedimiento anafórico adecuado: elección entre anáfora expresa y elipsis $(\$ 3)$ y elección entre paradigmas distintos $(\$ 4)$. El tercero $(\$ 5)$ concentra errores en la elección de la forma correcta del paradigma cuando ya se ha acertado en la elec- 
ción del procedimiento adecuado. En los dos primeros casos, nuestra descripción se organiza por la función sintáctica del elemento anafórico: referencia al sujeto oracional y a los argumentos verbales, por un lado, y referencia a complementos circunstanciales, por otro. En el tercer caso, la presentación se organiza por categorías gramaticales -formas de los pronombres demostrativos y adverbios locativos-, y no por funciones sintácticas.

\section{ERRORES EN LA OPCIÓN ENTRE ANÁFORA EXPRESA Y ELIPSIS}

El primer conjunto de datos que analizamos comprende errores debidos a una falta de dominio de los mecanismos que operan en la opción entre la anáfora expresa y la elipsis. Estos errores constituyen las dos caras de una misma moneda y afectan a formas lingüísticas que ejercen las mismas funciones sintácticas: sujeto, CI y, en menor medida, CD; además, se dan muchos problemas en la función de complemento circunstancial de lugar, con la presencia indebida de formas deícticas.

\subsection{Referencia al sujeto oracional y a los argumentos verbales}

3.1.1. Con sintagmas plenos: formas expresas con función contrastiva

Tratamos aquí los errores que afectan tanto a la elisión del sujeto oracional como a la del sintagma preposicional en función de CD y de CI. Aunque podría parecer que se trata de fenómenos distintos, el mecanismo lingüístico que determina la presencia o ausencia de estos sintagmas es el mismo y se relaciona con la estructura informativa del discurso, en especial, con la función informativa de foco contrastivo (cf. Zubizarreta 1999, pp. 427-432). En todos estos casos, la elipsis es la opción no marcada en cuanto a recuperación anafórica; esto es, si se mantiene el tema del texto o no se persigue contrastar el sujeto (o el CI o el CD) con ningún otro posible referente, no es necesario el uso del pronombre tónico. A este respecto señala Luján 1999, p. 1280:

Es indudable, pues, que las formas alternantes en la expresión/omisión del pronombre no tienen la misma función o valor significativo. La aparente alternancia libre es en realidad un caso de distribución complementaria. En una posición donde la omisión es posible, la forma explícita funciona como un término contrastivo, distintivo o «enfocado», que requiere un contexto discursivo, sea lingüístico o no, que justifique el énfasis que esta forma expresa. Esto es, un contexto que incluya o implique uno o más elementos a los que se contrapone el elemento enfocado. En tal entorno, la forma tácita, inacentuada, o no marcada, resulta, pues, disonante o inapropiada. 
Los primeros casos que presentamos corresponden a anáforas de sujeto, ejemplos todos de anáfora textual correferencial. Los textos que estudiamos reflejan un buen dominio de las reglas básicas para la elisión del sintagma sujeto; en este nivel, los estudiantes ya han entendido e interiorizado los mecanismos que determinan la presencia o ausencia del sujeto expreso, pero demuestran tener todavía problemas en determinados contextos sintácticos. En concreto, no siempre dan soluciones adecuadas a los usos en los que el sujeto oracional se resuelve con un pronombre personal con valor enfático o contrastivo (Luján 1999).

En los ejemplos de este tipo que encontramos, el cotexto tiene unas características comunes: en las oraciones anteriores existe más de un SN que puede funcionar como antecedente de la elisión, de modo que en ocasiones resulta necesario un pronombre explícito que deshaga la ambigüedad. Los errores documentados en el corpus parecen apuntar a que los estudiantes son conscientes de que es en estos contextos donde el español opta a veces por el pronombre expreso para la función de sujeto, pero a la vez muestran que desconocen las reglas que determinan la elección entre anáfora expresa y elipsis: tanto se hallan casos en los que se usa erróneamente un pronombre para deshacer una ambigüedad que en realidad no se produce, como casos en los que se opta indebidamente por una elipsis que altera el sentido de la oración.

En estos contextos, la correcta elección depende de factores relacionados con el desarrollo informativo del discurso: en una progresión de tema continuo, la opción correcta para la anáfora del sujeto temático es la elipsis. Ello explica la poca naturalidad de (6), donde el uso del pronombre él como sujeto supone una sobreespecificación incorrecta, dado que el mantenimiento del mismo tema en el discurso -el necesitado de la primera oración- requiere como mecanismo anafórico la elipsis $^{2}$ :

(6) Solo el necesitado se levantó de repente y salió tras del ladrón. Y le alcanzó. ¡Era increíble! Después el devolvió todos los bienes a la dueña del bolso.

[Después $\varnothing$ devolvió]

En cambio, cuando la progresión temática no es constante, sino lineal, el nuevo estatuto informativo de un referente, esto es, su condición de nuevo tema en el devenir discursivo, requiere ser marcado con una forma expresa. En estos casos, el error consiste en optar por la elipsis, generando así una estructura que es gramatical, pero cuya interpretación resulta distinta de la que tendría con el sujeto explícito. Así, en

\footnotetext{
${ }^{2}$ En los ejemplos tomados del corpus mantenemos siempre la ortografía y sintaxis de los textos originales. Únicamente cuando es necesario porque se produce ambigüedad, corregimos entre corchetes los errores ortográficos -como ocurre en los ejemplos (24) y (25)-.
} 
(7) la elisión del pronombre lleva a interpretar (erróneamente) que el sujeto elidido es correferente con el sujeto de la oración anterior:

(7) El ladrón no podía hacer nada debajo del peso del mendigo. $\varnothing$ Con el bolso en la mano regresó a la entrada.

[Este ... regresó]

En otros ejemplos, la presencia del pronombre no es solo innecesaria debido a la progresión temática, sino que la flexión verbal (o la concordancia de género) resuelve la posible ambigüedad. Así ocurre en (8), donde la flexión verbal de $3 .^{\underline{a}}$ persona únicamente permite interpretar que el antecedente del sujeto es mi amiga Michèle, y hace imposible interpretar que se mantiene el sujeto de la oración anterior, de 1. ․ persona:

(8) Esta mañana he visto a mi amiga Michèle. Ella me contó...

[ $\varnothing /$ quien me contó]

La función diferenciadora que cumple la presencia expresa del sujeto en los ejemplos analizados es muy similar a la que explica la elección entre la elisión y la expresión del SP que realiza la función de CI. No obstante, los errores que cometen los estudiantes en estos casos tienen una frecuencia mucho menor, tal vez porque otras lenguas que conocen funcionan en este sentido de forma parecida ${ }^{3}$ : el CI solo se ha de expresar con sintagma pleno cuando hay cambio de tema en el discurso; en caso contrario, el sintagma es superfluo, porque ya queda recuperado por el clítico.

Esto explica la obligatoriedad de la presencia del SP de CI en (9): el CI es tema oracional (distintivo) -por ello ocupa posición inicial-, por lo que su presencia es obligatoria por motivos de contraste (cf. Fernández Soriano 1999, p. 1230):

(9) un edificio muy impresionante desde el punto de vista arquitectónico, y es cierto que esa gente tiene razón. Sin embargo, lo que $\varnothing$ me gusta hacer cuando voy allí es...

[lo que a mi me gusta hacer]

En cambio, en (10) el SP a mí explicita un CI de forma innecesaria, puesto que se mantiene el tema de la oración anterior:

(10) Había decidido ir de compras, porque era el cumpleaños de una amiga mía y a mí me faltaban unos zapatos.

[y $\varnothing$ me faltaban unos zapatos]

\footnotetext{
${ }^{3}$ Aunque en este estudio no hemos tenido en cuenta las lenguas maternas de los estudiantes, conviene recordar que todos ellos provienen de universidades europeas, en especial británicas, francesas y alemanas. Por ello, podemos suponer que muchos de ellos conocen el inglés, el francés y el alemán.
} 
Nótese que en el caso de los complementos verbales -CD y CI-, la opción menos marcada en cuanto a contraste es la que expresa la anáfora mediante un clítico, y la opción marcada es la que se realiza con la repetición léxica o con el empleo de un pronombre tónico, como en (11) y (12), ejemplos de los escasos errores que hemos hallado en la expresión anafórica del CD:

(11) Entonces se levantó el mendigo, dejó la flauta y se echó a correr a toda prisa siguiendo el ladrón. Cuando alcanzó el ladrón...

[Cuando lo alcanzó]

(12) Nadie se movió, incluso los guardias de seguridad, quienes miraron de manera desinteresada. Ningún miembro del público intentó ayudarla a ella.

[intentó ayudarla]

En estos casos no se da propiamente una anáfora por elipsis, sino la opción entre expresión u omisión del SN o del SP que realiza la función de complemento, pero siempre existe un clítico que expresa esta misma función. Por eso, en nuestro corpus no hallamos en rigor errores de anáfora por elipsis indebida, salvo con determinados verbos en los que parecen intervenir factores relacionados con el conocimiento léxico y la estructura argumental del predicado más que con el dominio de la anáfora, como analizamos en el apartado siguiente.

\subsubsection{Errores en el uso de los clíticos de CI y CD: estructura argumental y estructura informativa}

Analizamos aquí un grupo de errores que presentan particularidades propias, con problemas que originalmente no están vinculados con la anáfora, si bien esta puede entrar en combinación con ellos. No se corresponden, pues, con ninguna de las categorías que hemos establecido en nuestra tipología de la anáfora; se trata de errores relacionados con los clíticos de CI, cuya presencia expresa viene exigida por razones de semántica léxica, y ocasionalmente también por razones de orden sintáctico.

En un primer conjunto de casos, la presencia obligatoria del clítico se debe a factores relacionados con la estructura argumental del verbo bien descritos por la gramática. Así, el clítico debe aparecer, como afirma Gutiérrez Ordóñez 1999, p. 1872, «cuando precede a un complemento indirecto no argumental, es decir, no previsto en la valencia del verbo»), como observamos en (13):

(13) Al final la señora busca en el bolso una moneda $\varnothing$ la echó al mendigo quien la agradeció.

[se la echó al mendigo] 
Algo similar ocurre en (14), con un verbo que se puede usar sin CI (hacer); el complemento es, pues, no regido, por lo que la presencia del clítico es obligatoria:

(14) Se acercó a la mujer de detrás, $\varnothing$ hizo un truco de judo, le quitó el bolso...

[le hizo]

El clítico es también obligatorio cuando el objeto canónico es un pronombre (Fernández Soriano 1999, p. 1248). En este sentido, la forma usted tiene un comportamiento algo distinto (el clítico es elidible en algunas ocasiones), no siempre fácil de explicar. Por ello, es comprensible el error del estudiante:

(15) Hoy en día, es tan raro ver un poco de amabilidad en una gran ciudad, que yo sentí una gran responsabilidad decir $\varnothing$ lo a ustedes.

[decírselo]

En un segundo conjunto de ejemplos, en cambio, la obligatoriedad de la presencia del clítico de indirecto responde a otros factores, no claramente resueltos por las descripciones gramaticales. Se trata de verbos triactanciales, que introducen un CI con papel temático de destinatario (dar, entregar, devolver, etcétera):

(16) Luego $\varnothing$ entregó el bolso a la señora y se puso a tocar la flauta de nuevo.

[le entregó]

Según se aduce (cf. Fernández Soriano 1999, p. 1250), la reduplicación es potestativa ( $\mathrm{si}$ bien es la opción preferida) cuando el CI recibe el papel temático de destinatario. Por ello, las dos opciones (presencia/ ausencia del clítico) deberían ser posibles y equivalentes. Sin embargo, en nuestros ejemplos la elisión produce oraciones anómalas. Nuestra hipótesis es que en casos como estos la opción por una u otra alternativa no es libre, sino que está condicionada por factores cognitivos, tal vez relacionados con la percepción de la referencia como «fondo» $\mathrm{o}$ «figura» (cf. López García 1994, vol. I, p. 7; 1996, vol. II, pp. 5 y 466-470): la ausencia del clítico da más importancia a la acción del sujeto oracional -aporta información sobre la acción que este hace-, pero deja fuera del foco al CI; en cambio, la presencia del clítico informa además sobre las repercusiones que dicha acción tiene sobre el CI. Dicho en otros términos, la presencia del clítico marca que tanto el sujeto como el CI están activados desde un punto de vista cognitivo: se aporta información sobre cómo la acción del verbo afecta a ambos.

Además, hemos identificado un tercer conjunto de ejemplos en que el error parece deberse a que el estudiante desconoce la estructura argumental del verbo. En (17) el predicado exige necesariamente un CI; 
dado que el complemento está regido por el verbo, se ha de expresar bien con el SP pleno, bien con un clítico:

(17) Un joven que estuvo detrás de la mujer la derribó y $\varnothing$ arrebató el bolso.

[y le arrebató el bolso]

Tal vez, en este caso el estudiante se confunde porque el español tiende a expresar con un CI complementos que en otras lenguas se expresan mediante un complemento que designa el poseedor: arrebató el bolso de la mujer. En cierto sentido, es un caso similar al que suponen los complementos de posesión inalienable: le arregló el pelo/arregló el pelo de la mujer. De hecho, en numerosas ocasiones los datos de nuestro corpus presentan errores debidos a que se analiza un complemento como de posesión inalienable y el estudiante usa en consecuencia un posesivo en lugar de un artículo:

(18) Un hombre muy joven se acercó a ella y le robó su bolso... [el bolso]

(18) es un ejemplo muy claro de interferencia de otras lenguas, en que estos complementos suelen introducirse mediante posesivos. La estructura equivalente en español supone expresar lo que en otras lenguas es un poseedor mediante un CI y, en consecuencia, debe aparecer el clítico correspondiente a esta función:

(19) había arrebatado la bolsa de mano de la mujer

[le había arrebatado $e l$ bolso a la mujer]

El desconocimiento de la estructura argumental del verbo parece ser también el factor que explica los escasos errores en que los estudiantes muestran tener problemas con la presencia o ausencia del clítico de CD. Este problema afecta a un número de verbos reducido, como negar o agradecer. Negar es un verbo que modifica su semántica en función de la presencia o ausencia de clíticos: negar (tema: un contenido informativo), negarse a algo (tema: una acción), negarle algo a alguien (tema: un objeto = una autorización; requiere un destinatario). Se puede postular, por tanto, que en (20) el error radica en una falta de conocimiento de la semántica y la gramática del verbo:

(20) Cuando pasó una mujer que fue vestida muy distinguida, le tendió la mano para pedirle una limosna. Pero ella $\varnothing$ negó y aceleró su marcha, diciendo que no tenía tiempo.

[Pero ella se la negó]

En cuanto al verbo agradecer, origen de muchos errores en nuestro corpus, los estudiantes eliden el clítico de CD cuando este se debería recuperar con una anáfora expresa, como en (21): 
(21) Ella quiso darle un billete para agradecerle $\varnothing$ pero, para el asombro general, se negó en aceptar.

[agradecérselo]

La combinación de dos pronombres (un clítico de CD y otro de CI) puede ser un problema añadido en ejemplos como (21), que, de otro modo, serían fáciles de resolver para los estudiantes. Una tercera vía para explicar el error atendería a la posibilidad que presenta el español de elisión del CD: todos los verbos que aquí aparecen pueden usarse en sentido absoluto (esto es, sin CD); sin embargo, ello no es posible en estos casos porque el complemento del verbo aparece citado explícitamente con anterioridad, y por lo tanto ha de ser recuperado anafóricamente.

También es el desconocimiento de la estructura argumental del verbo lo que parece explicar los pocos casos de reduplicación innecesaria del clítico de $\mathrm{CD}$ :

(22) Como el mendigo era muy deportivo, le alcanzó al ladrón rápidamente...

[ $\varnothing$ alcanzó al ladrón]

Todos ellos responden a un mismo patrón: el CD es un SN cuyo referente es una persona; por ello, va precedido de la preposición $a$. Podemos, pues, postular que el estudiante analiza mal la oración y confunde el CD con un CI. Por ello, usa el pronombre $l e^{4}$ y aplica la regla de reduplicación del clítico de CI -correctamente según el análisis erróneo que hace-.

\subsection{Referencia a complementos circunstanciales de lugar}

El último conjunto de errores debidos a falta de dominio de los mecanismos de elipsis lo encontramos en casos de anáfora en función sintáctica de CCL. Nuestros estudiantes resuelven siempre estos casos con la presencia de una anáfora expresa, cuando lo esperable sería una elipsis. Son, pues, ejemplos de un tipo de anáfora textual correferencial a una entidad.

Como es sabido, para los complementos de lugar, donde otras lenguas optan por un clítico, el español no usa pronombre anafórico alguno. Por ello, utilizar un deíctico con tal función da como resultado una información redundante, salvo que sea un pronombre con valor contrastivo (se trata de un fenómeno muy similar al de la elisión de sujeto). Aquí radica la mayor parte de los errores que aparecen en los datos de

\footnotetext{
${ }^{4} \mathrm{El}$ hecho de que en dos ocasiones en nuestro corpus sea un SN femenino excluye la posibilidad de leísmo.
} 
nuestro estudio. Podemos clasificar estos errores en dos grupos: los que se producen con verbos estativos (ejemplos 23 a 26) y aquellos que se producen con verbos de movimiento (27 y 28 ).

En el primer grupo predominan los errores asociados a los verbos estativos haber y estar. Este predominio podría hacer pensar en una interferencia de otras lenguas como el inglés (there is) o el francés (il y a), en las que el deíctico anafórico (presente etimológicamente en el espanol hay) aparece externo al verbo. El uso indebido de estos deícticos induce al lector a asignarles una función contrastiva y a interpretar que el lugar al que remite la anáfora se contrapone a otros que él pudiera tener en su mente:

(23) Ayer vi algo increíble en el centro comercial. Allí había un mendigo tocando la flauta cerca de los escaparates...

[ $\varnothing$ Había un mendigo]

De nuevo una alternativa (la del adverbio expreso en contraste con la elipsis) no es libre, sino que está condicionada por factores cognitivos, similares a los que explican el uso del clítico en función de CI examinado en el apartado anterior. En esta ocasión, la presencia del adverbio otorga mayor importancia al espacio en que sucede la acción.

Otros casos en los que el estudiante ha optado por una anáfora expresa, cuando lo esperable hubiera sido una elipsis, presentan el problema adicional de la correcta elección de la forma expresa (v. infra $\$ 4.2$ ):

(24) Miré hacia dónde [donde] había estado el mendigo, para ver si él era el cómplice del ladrón, pero no estaba ahí.

[no estaba $\varnothing /$ allí

En los ejemplos (25) y (26) el problema en el uso de la anáfora se combina con otras dificultades en la interlengua de los estudiantes:

(25) Ayer vi un hombre, o más bien un mendigo afuera del Corte Inglés. Estaba sentado en la tierra alli tocando la flauta. Pedía limosna de todas las personas que paseaban [pasaban] por allí. Le había visto muchas veces alli.

[Le había visto muchas veces $\varnothing$ ]

(26) Soy de un pueblo del norte de Suecia que se llama Umea. Allí me crié y viví allí hasta que cumplí 19 años.

[ $\varnothing$ Me crié y viví allí]

En (25), la primera anáfora (en la tierra allí) parece corresponder a una interferencia frecuentemente observada en la producción de los estudiantes de ELE, cuando usan el locativo en lugar de un demostrativo o de un complemento especificativo del nombre anterior, en una anáfora que el español resolvería (si fuera necesaria) mediante SN: en el 
suelo del centro comercial; de otro modo habría cabido esperar estaba alli, sentado en el suelo. La segunda y la tercera pertenecen al grupo (visto supra) de los usos de un deíctico con función contrastiva: Alli precisamente, y no en otro lugar, lo había visto muchas veces. En (26), a su vez, habría bastado con uno cualquiera de los dos locativos. La posición inicial del primero de los dos es correcta, por cuanto representa el tema oracional; pero, si se desea hacer una repetición enfática, entonces también el segundo locativo debería ir al principio de su frase: allí me crié y allí viví.

En cuanto a los verbos de movimiento, su especificidad viene determinada por la necesidad de hacer referencia al lugar de origen o de destino de ese movimiento. La cuestión se complica con la diferente distribución del campo referencial en la deixis espacial (ir/venir, llevar/traer) que presenta el español frente a otras lenguas. En (27) (aparte de la elección errónea del primer verbo, que debería haber sido voy), la anáfora expresa en el segundo es redundante, o bien enfática. El verbo ir usado con el reflexivo lleva ya implícita la referencia a un lugar que se abandona; si el lugar ha sido ya mencionado, la elipsis es obligada y es imposible interpretar el deíctico como contrastivo: irse se interpreta siempre como irse del lugar en que se estaba:

(27) Vengo a la pista [...] Me voy de alli sonriendo.

[Me voy $\varnothing$ sonriendo]

Finalmente, en (28) el estudiante ha optado por la repetición léxica cuando la elipsis era suficiente. Probablemente esté actuando aquí la misma percepción de la necesidad de una anáfora expresa que en otras lenguas se resuelve mediante un clítico.

(28) De camino a casa estaba un poco inquieta porque quería volver directamente a casa después de...

[volver directamente $\emptyset$ ]

\section{ERRORES EN LA ELECCIÓN ENTRE PARADIGMAS DISTINTOS}

Otro gran conjunto de errores de nuestro corpus de estudio comprende un amplio abanico de casos que tienen en común el hecho de que en todos ellos el estudiante utiliza una forma anafórica expresa en un contexto en que la lengua así lo exige, pero yerra en la forma que elige. Este error puede traducirse en dos fenómenos distintos. En unos casos, se utiliza una forma perteneciente a un paradigma distinto del que el contexto requiere (artículo por demostrativo, pronombre átono por tónico, etc.); son los problemas que analizamos en el presente epígrafe. En otros se elige una forma incorrecta de un paradigma adecuado-problemas que abordamos en $\$ 5$-. Todos estos casos constituyen ejemplos de anáfora textual correferencial a una entidad, con diversos tipos de error. 
$\mathrm{Al}$ igual que hacíamos en el apartado anterior, agrupamos los errores según la función sintáctica que desempeña la forma anafórica: por un lado, errores que atañen a formas con la función de sujeto o de argumento verbal; por otro, formas con función de complemento circunstancial. Si bien algunos de los mecanismos que parecen actuar como desencadenante del error son los mismos en unos y otros casos -especialmente los relacionados con la focalización y la función contrastiva-, las peculiaridades de las distintas formas implicadas en cada caso aconsejan un estudio diferenciado.

\subsection{Referencia anafórica al sujeto y a los argumentos verbales}

Se puede establecer una gradación respecto a la función contrastiva que desempeñan los distintos procedimientos anafóricos en español: desde formas que aportan un mayor énfasis o contraste hasta formas que no focalizan la entidad a la que remiten. Según ello, la repetición léxica con énfasis prosódico sería el procedimiento más marcado de focalización, seguido del pronombre personal tónico o el demostrativo, que tiene valor contrastivo pero no focal, y del pronombre personal átono (CD y CI) o la elipsis (sujeto), ambos sin capacidad distintiva.

Atendiendo a esta gradación, se puede postular que en (29) el estudiante desconoce el carácter focalizador que tiene la anáfora por repetición léxica en español. En efecto, este mecanismo anafórico se suele utilizar únicamente cuando la repetición está acompañada de énfasis acentual en estructuras focalizadas (Luján 1999, p. 1298), dado que el pronombre tónico ya cumple por sí solo la función contrastiva:

(29) Todavía no entiendo por qué el mendigo no quería aceptar más dinero $[. .$.$] y por qué la mujer no le dio más dinero aunque el mendigo$ no quería aceptarlo.

[aunque él no quería]

En casos como en (30), en cambio, la solución -errónea- que ha elegido el estudiante vuelve a ser la repetición del SN, si bien la adecuada resolución del contraste se complica en este ejemplo debido a la complejidad del sistema de demostrativos del español:

(30) ... salió detrás del atracador. Aunque el atracador corrió... [Aunque este corrió]

Tal como examinamos más adelante $(\S 5.1)$, el sistema de los demostrativos es uno de los más complejos del español, tanto por su estructura interna como por sus diferentes usos para funciones exofóricas y endofóricas. De Kock 1990 ha estudiado la diversidad y heterogeneidad de los usos anafóricos del demostrativo en español y su variación en función del tipo de texto, del modo oral o escrito y de la forma del de- 
mostrativo (flexivo o neutro, como pronombre o como adjetivo). En (30), por ejemplo, procede usar el adjetivo demostrativo flexivo del campo referencial de $1 .{ }^{\underline{a}}$ persona, de una gran frecuencia en posición inicial de la frase en la prosa escrita, casi como un elemento de conexión, según la descripción de De Kock.

\subsection{Referencia a circunstanciales}

Los problemas recogidos en este apartado afectan a dos zonas conflictivas en la elección del procedimiento anafórico: la representación discursiva de la realidad objetiva $(\$ 4.2 .1)$ y el señalamiento discriminante de la anáfora expresa (\$ 4.2.2). Los presentamos agrupados bajo los problemas que afectan a los circunstanciales por ser estos los errores más típicos, si bien no siempre parece tratarse de problemas exclusivos de estos complementos, pues algunos afectan en el mismo grado a argumentos verbales.

Como señala la lingüística cognitiva (Langacker 1987, Castañeda Castro 2004), mediante los recursos lingüísticos se pueden ofrecer alternativamente representaciones diversas de una misma realidad, esto es, representaciones discursivas distintas de una misma situación. Ello puede tener su origen en la existencia de diversas opciones en el propio sistema, pero también en la propia configuración del sistema, que contrasta con el de otras lenguas. En el caso que nos ocupa, debe presentarse adecuadamente a los estudiantes el modo en que el español categoriza ciertas realidades, pues los errores en la elección de la forma anafórica que hallamos son reflejo de un problema cognitivo más que propiamente gramatical. Así, la elección entre diferentes series deícticas responde a la representación lingüística de una realidad que puede categorizar un componente de la situación, bien como una circunstancia de modo, bien como una entidad; el español tiene preferencia por determinadas opciones modales: asi es un día en la vida de $X$, frente a expresiones habituales en hablantes extranjeros, como eso es un día...; o, también, como hemos demostrado, que los alumnos suelen formular con el clítico anafórico añadido al adverbio modal, como lo hemos demostrado.

La segunda zona de conflicto es la que afecta al señalamiento discriminante de un antecedente de la anáfora, que puede comportar efectos de contraste o de énfasis sobre ese mismo antecedente. En la progresión temática del texto, como hemos señalado más arriba, existen circunstancias en las que, para evitar posibles ambigüedades, hay que recuperar un referente mediante una anáfora expresa; pero en otras ocasiones, además de resolver la posible ambigüedad, se desea contrastar el referente al que remite la anáfora con otros posibles referentes presentes en el contexto, o bien destacarlo por razones diversas. 


\subsubsection{La representación discursiva de la realidad}

El primer problema que analizamos incluye los errores debidos a la confusión entre dos series deícticas, reflejada en el uso de un demostrativo en lugar de un adverbio o viceversa. Se trata siempre de casos de anáfora textual difusa, referida a proposiciones.

Tal vez pueda proponerse, ante la falta de estudios específicos sobre el tema, que la falsa elección de la serie deíctica responde a una categorización de la realidad distinta en español y en la L1 de los alumnos. Son errores que se producen en sintagmas en función de sujeto, atributo y otros complementos del verbo, bien porque el estudiante categoriza el antecedente como una entidad, cuando en español es más frecuente hacerlo como un modo -ejemplo de (31)-, bien porque se produce lo contrario y el estudiante categoriza como un modo algo que en español no se concibe como tal -ejemplo de $(32){ }^{5}$ :

(31) Esto es un día típico de verano.

[Así es un día]

(32) Siempre ocurre así.

[Siempre ocurre lo mismo]

Por otro lado, en la referencia a circunstanciales, los textos que analizamos contienen un grupo de enunciados cuyo problema radica en anular la prominencia del referente del circunstancial, como consecuencia de haber descartado el clítico de CI y optado por otro procedimiento anafórico; es lo que puede observarse en (33):

(33) No pedía limosna, solo estaba sentado ahí mirando a la gente que pasaba delante de él.

[le pasaba por delante]

A pesar de que ambas soluciones son posibles en español, para anáforas como esta se opta preferentemente por el clítico de CI (Demonte 1995), de forma análoga a como se hace con el dativo ético, el CI duplicado o el clítico en lugar del posesivo en las construcciones de posesión inalienable (cf. § 3.1.2); en todos estos casos se trata de una opción expresiva de la lengua para representar un hecho objetivo como una experiencia personal de alguien. En nuestros ejemplos, la expresión pasar por delante de él despoja al referente de la anáfora de cualquier

\footnotetext{
${ }^{5}$ Procede recordar a este respecto (y al respecto de los ejemplos que siguen) cómo Hymes 1971 en su trabajo sobre la competencia comunicativa incluye el conocimiento no solo de lo que el sistema admite, sino de lo que se da de facto en el uso de la lengua, consideración que implica que el sistema tiene posibilidades que nunca llegan a actualizarse; este podría ser uno de esos casos.
} 
componente experiencial, mientras que pasarle por delante lo convierte en experimentador de un suceso.

Este fenómeno, no obstante, requeriría de una descripción mayor que la que aquí se presenta, pues está sometido a fuertes restricciones que impiden, por ejemplo, que la construcción con clítico sea posible en (34), en cierto sentido el reverso de (33), pues no admite la construcción le estaba detrás:

(34) Al mismo tiempo que salí de la galería, la misma mujer que yo había visto salió de la puerta de cristal de la galería. Un joven que estuvo detrás de la mujer la derribó.

[detrás de ella la derribó]

A falta de estudios específicos sobre el tema, podemos avanzar la hipótesis de que es el distinto modo de acción del verbo -un proceso en (33) frente a un estado en (34)- lo que determina este contraste. El ejemplo (34) además ofrece otra particularidad que nos sitúa ya en la segunda zona conflictiva que abordamos en el siguiente apartado: se requiere la anáfora expresa para señalar un circunstancial, dado que con la elipsis se hubiera transmitido una información diferente: el joven del ejemplo aparecería situado detrás de la puerta y no detrás de la mujer.

4.2.2. El señalamiento discriminante: los procedimientos de anáfora expresa de circunstanciales

Uno de los procedimientos para la anáfora expresa es el uso del pronombre personal. En la referencia a circunstanciales, este parece ofrecer la opción menos marcada en cuanto a énfasis o contraste ${ }^{6}$. Por ello, en (35) el estudiante debería haber optado por una anáfora expresa mediante un SP con un pronombre personal, pues no se requiere introducir contraste con otros posibles antecedentes:

(35) Creo que lo único que me va [voy] a echar de menos al regresar a mi ciudad serán las personas que he encontrado aquí y las situaciones que pasé con aquellas personas.

[con ellas]

Frente a esta opción no marcada, el español puede optar también por la repetición léxica, con carácter enfático. En tal caso, el nombre repetido necesita de un actualizador, lo que comporta de inmediato otra opción más: cuál debe ser este actualizador, el artículo o el demostrati-

\footnotetext{
${ }^{6}$ Es interesante observar que no sucede lo mismo en la referencia a sujetos, en la que la opción menos marcada es la de la elipsis, y la anáfora expresa es enfática o contrastiva (v. supra $\$ 3.1 .1$.
} 
vo (y, nuevamente, en este caso, cuál de los tres). Nota Fernández Ramírez 1987, p. 103, que ambos paradigmas -artículo y demostrativo- sirven para identificar sin clasificar; pero mientras que el señalamiento del artículo es individualizador, el del demostrativo es discriminante, además de comportar una gradación de proximidad. La opción por la repetición léxica aparece como portadora de un elemento de énfasis en los dos casos (añadido al contraste, en el caso del demostrativo); la opción por el demostrativo en función pronominal (sin repetición léxica, por tanto) se limita a la discriminación.

Desde la lingüística textual el problema puede explicarse en términos de progresión temática, según cómo sea interpretada la información que introducen estos elementos: información temática o remática. Es una cuestión de cómo se gestiona la información en el avance discursivo, según podemos observar en (36):

(36) Entonces le acercó un hombre que de repente cogió su bolso de mano y se echó a correr. Todos nos quedamos paralizados a causa de la acción.

[a causa de esa acción]

Este ejemplo tiene la particularidad de que presenta dos procedimientos anafóricos complementarios: en primer lugar, se recupera como referente toda una proposición, mediante el procedimiento de la anáfora difusa (acción es el término con que se designa la conceptualización de la proposición recuperada con la anáfora); en segundo lugar, el sustantivo que ejerce esta función está actualizado con un determinante. El estudiante, pues, debe decidir acerca del actualizador. Al elegir el artículo, ha categorizado cognitivamente la acción como tema del discurso, cuando no lo es; por ello, se requiere un demostrativo para recuperar un referente que ya ha dejado de ser tema en este enunciado.

El ejemplo (37) constituye una muestra del mismo procedimiento, pero con la opción inversa a la que presentaban los anteriores: el estudiante ha elegido el demostrativo para destacar un referente en el texto que es el tema del discurso, por lo que lo más apropiado sería recuperarlo con un artículo determinado:

(37) La mujer que yo había visto hace un rato [...] estaba en el suelo - sin ese bolso.

[sin $e l$ bolso]

En (38), en cambio, el estudiante ha optado por la repetición léxica, cuando la simple referencia al lugar mencionado, sin valores enfáticos o contrastivos añadidos, se resuelve satisfactoriamente con el locativo. En este caso la opción menos informativa es el uso del adverbio de lugar. Si se desea destacar el carácter de ciudad, entonces se recurre al pronombre personal: para quedarme mucho tiempo en ella. 
(38) Mi ciudad se llama Malmö en Suecia. No tuve bastantes días libres de la escuela para quedarme mucho tiempo en Malmö.

[quedarme mucho tiempo alli / en ella]

Estos ejemplos no hacen más que evidenciar la complejidad que entraña la recuperación anafórica de los complementos circunstanciales. Así, si en (35) la opción preferible es el pronombre personal; en (36) es el nombre común precedido del demostrativo; en (37), el artículo determinado, y en (38), el locativo.

\section{ERRORES EN LA ELECCIÓN DE LA FORMA CORRECTA DEL PARADIGMA ADECUADO}

Un último conjunto de errores que abordamos atañe a la opción por un miembro incorrecto de un paradigma adecuado, en particular de uno de los paradigmas trimembres del español: demostrativos y locativos. Esto no puede resultar extraño si se tiene en cuenta tal peculiaridad del español, que lo distingue de la mayor parte de lenguas que conocen los estudiantes, con solo dos miembros en estos paradigmas. Esta diferencia es un primer factor de dificultad, al que se añaden otros: por un lado, debe destacarse la enorme variación que presentan los usos de estos paradigmas según cuál sea su función (endofórica o exofórica), el canal (oral o escrito), o el tipo de texto (expositivo, narrativo...). Como ha puesto de relieve el ya citado trabajo de De Kock 1990, en el interior del paradigma se configuran subsistemas donde uno de los miembros desaparece en determinados contextos: por ejemplo, en la referencia anafórica dual en la prosa escrita, las opciones se limitan al par este-aquel, con señalamiento del más próximo o lejano respectivamente, quedando descartado todo uso de ese; también describe el problema de la elección entre este/ese en la autorreferencia singular y su diferente distribución en la prosa oral o la escrita; y asimismo la ya comentada preferencia del español por el demostrativo este (tanto en función adjetiva como pronominal) cuando va al inicio de la frase en la prosa escrita. Por otro lado, conviene señalar el valor etimológico eminentemente señalador del demostrativo ese, que lo hace especialmente adecuado para la mención evocativa, es decir, un tipo de anáfora que remite a entidades o proposiciones presentes en el contexto cognitivo, pero no en el cotexto. En último lugar, la presencia de formas neutras y su particular modo de referencia suponen un problema añadido, no tan simple como a primera vista pudiera parecer, como se verá. Por todas estas razones, en este apartado testimoniamos abundantes errores asociados a tipos de anáfora apenas abordados en los apartados anteriores: la anáfora difusa y la deixis cognitiva. 
El parentesco entre el paradigma de los demostrativos (\$5.1) y el de los adverbios locativos ( $\$ 5.2)$ hace plausible suponer análogas dificultades en la opción por el miembro correcto en cada caso.

\subsection{Pronombres demostrativos}

En el paradigma de los pronombres demostrativos, son significativos los casos en que los estudiantes emplean el demostrativo este con función anafórica para recuperar el referente que se acaba de mencionar, presente en el texto pero no en el contexto empírico de quien escribe o lee ${ }^{7}$. Puede observarse este problema en (39):

(39) Cuando uno pasa un año o más en otro país, a veces se siente tan bien en este lugar que ya no quiere volver a su tierra.

[ese lugar]

La confusión que ilustra este ejemplo, bastante frecuente en los textos que analizamos, es consecuencia de no haber interpretado adecuadamente el tipo de anáfora que vehicula el demostrativo. El estudiante, erróneamente, supone que se trata de una anáfora textual correferencial, por lo que usa el demostrativo del campo referencial de $1 . \underline{a}$ persona debido a la proximidad del antecedente (pais) en el cotexto. Sin embargo, estamos ante una deixis cognitiva, pues la introducción del antecedente (pais) evoca un conocimiento compartido (un tipo de país que consideramos ideal para quedarse) al que refiere el demostrativo. El error radica, así pues, en no reconocer la mención evocativa del demostrativo ese, una clase de señalamiento a un objeto no presente en la situación de enunciación o a un objeto inmaterial, realizado como si estuviera presente (Fernández Ramírez 1987, p. 119) ${ }^{8}$.

\footnotetext{
7 Son, en cambio, muy poco numerosos en nuestro corpus los casos en los que los demostrativos se usan con valor exofórico y no anafórico. Uno de los pocos ejemplos que hallamos es el siguiente, en que el estudiante comete un error en la opción entre el demostrativo y el artículo:

(i) Mi bolsa, mi bolsa. $\mathrm{El}$ mendigo me la ha robado. [ese mendigo]

En este ejemplo se da un caso de deixis ad oculos: es un fragmento en discurso directo en que el personaje al que se alude está en el campo mostrativo de los interlocutores, por lo que se ha de marcar con un demostrativo ese; este señalamiento no lo realiza el artículo determinado.

${ }^{8}$ El reverso de esta confusión es el que muestra el siguiente ejemplo, una interpretación equivocada de una mención evocativa en lugar de una anáfora textual:

(i) En tercer lugar, un poco menos divertido, tendré que poner al día unos papeles, tendré que matricularme en la universidad, buscar un trabajo de estudiante, buscar una práctica de tres meses en Irlanda para el mes de marzo... Todas esas obligaciones no me dejarán mucho tiempo para pensar en los momentos maravillosos que viví en Barcelona. [estas obligaciones]
} 
El ejemplo (40) refleja también la misma confusión por parte del estudiante, aunque debería haberse resuelto por aquella (y no por esa) -en la deixis cognitiva es predominante el uso de ese, pero puede aparecer también aquel en narraciones en pasado (Fernández Ramírez 1987, p. 123)-:

(40) Me parecía ilógico que alguien se sentara en la calle pidiendo dinero a cambio de escuchar una canción y no aceptara una donación por su acto heroico de salvar las propiedades de esta señora.

[aquella señora]

El error nace de interpretar que se trata de recuperar un referente discursivo (este, el que acabo de mencionar) y no anclado en el momento de la enunciación (ese, el evocado, en el que sitúo la narración). Parece darse una confusión entre el tiempo de la narración y el tiempo de lo narrado.

Un problema distinto es el que presenta la serie de ejemplos que sigue, donde el estudiante usa un SN cuyo núcleo conceptualiza anafóricamente lo dicho en el discurso precedente por medio de una anáfora difusa. En este tipo de anáfora, según Fernández Ramírez 1987, p. 126, el español tiene preferencia por el demostrativo ese frente a los otros $\operatorname{dos}^{9}$, lo cual explica el error de (41). Aquí, el sustantivo momento recoge correferencialmente la proposición hasta que el corazón demande parar para instalarse; es, pues, una anáfora difusa que debería usar la forma del demostrativo de 2. ${ }^{\mathrm{a}}$ persona:

(41) Hay que buscar una buena mezcla entre ambos sitios, es decir no quedarse demasiado tiempo ni en un lugar ni en otro, hasta que el corazón demande parar para instalarse. Hasta este momento mi perra tendrá que esperarme un poco más aunque siempre volveré a verla.

[Hasta ese momento]

Algo más compleja es la explicación de (42), para la cual hay que recurrir a la secuencia de procesos que llevan a la solución impuesta o preferida por el español. En primer lugar, estamos ante la recuperación anafórica de una proposición, para la que el español suele recurrir al demostrativo neutro (en una de las tres opciones del paradigma); en segundo lugar, la opción por el procedimiento de la anáfora difusa, formando un concepto nuevo (problema) para el contenido proposicional recuperado y seleccionando el demostrativo de $2 .^{\underline{a}}$ persona, daría la anáfora ese problema como sujeto de la frase; en tercer lugar, se da una elipsis de este recién introducido sustantivo y su traslado a la posición

\footnotetext{
${ }^{9}$ Un caso particular es el del demostrativo neutro esto en lugar de eso en el conector por eso, fuertemente lexicalizado; un ejemplo de nuestro corpus: «Yo creo que sí, y por esto, la visita» [por eso].
} 
de atributo de la oración: ese (problema) no era su problema. Se trata de una opción estilística del español muy frecuente para este tipo de enunciado:

(42) Incluso el guarda de la puerta se quedo paralizado y además vi una expresión en su cara que decía que esto no era su problema. El era responsable para lo que pasaba dentro de la tienda, pero no de lo que pasaba enfrente de esta.

[eso/ése]

En (41) y (42), pues, los estudiantes usan los demostrativos este y esto con valor anafórico, como anáforas textuales correferenciales que remiten al lugar o el momento que se acaba de mencionar en el discurso. En cambio, la solución más apropiada en estos casos sería la de una anáfora difusa, que prefiere el demostrativo de $2 .^{\underline{a}}$ persona.

\subsection{Adverbios locativos}

Otro problema en la selección del miembro correcto afecta a los locativos ahi y alli; las dificultades pueden originarse en la confusión entre el valor exofórico y el endofórico de estas unidades. Es lo que puede haberle sucedido al estudiante en (43):

(43) ... y vamos directamente hasta el Café Creem que está muy cerca. Ahí compramos...

[alli compramos]

La confusión, de nuevo, se debe a que los sistemas de otras lenguas que conocen los estudiantes establecen una distinción entre dos formas, cuando el español tiene tres. Curiosamente, y en contraste con los anteriores, aquí los estudiantes usan la forma del campo referencial de 2. ${ }^{\text {a }}$ persona (ahi), tal vez porque creen erróneamente que es la que funciona en una especie de deixis cognitiva que no rige, sin embargo, en la serie de los locativos, o tal vez por la proximidad discursiva del antecedente; pero deberían usar la forma alli para referirse al lugar de lo enunciado, alejado en la narración (y, por tanto, de quien escribe y de quien lee).

\section{Conclusiones}

Los errores en las producciones escritas objeto de nuestro estudio responden a patrones distintos en función del tipo de anáfora que se lleva a cabo en cada caso. En muchas ocasiones, la confusión nace del hecho de que se utilizan las mismas unidades lingüísticas (los demostrativos, por ejemplo) tanto para valores deícticos como anafóricos, o bien se debe a que en la interpretación del referente se confunde el 
señalamiento textual con el señalamiento situacional. En este sentido, los textos analizados ofrecen un nutrido conjunto de datos en los que los estudiantes muestran vacilaciones en la correcta identificación del campo -textual, cognitivo o situacional- al que debe remitir una forma anafórica. En otras ocasiones, en cambio, el origen del problema parece estar relacionado con cuestiones propias de la estructura informativa $y$, en especial, con las esquivas nociones de foco y contraste.

En efecto, en el contexto del propio texto (el cotexto), los estudiantes parecen haber comprendido las reglas fundamentales que rigen el empleo de las formas anafóricas. Los problemas de uso que presentan se relacionan fundamentalmente con la estructura informativa de la oración: la confusión entre tema discursivo y tema oracional provoca en ocasiones el uso de una anáfora expresa incorrecta. En tales casos, los estudiantes explicitan innecesariamente con un pronombre tónico el tema de una oración que también es tema del discurso en una progresión de tema constante; si no se debe a un énfasis motivado pragmáticamente, resulta redundante destacar el tema que trata la oración cuando es el mismo que el del discurso al que remite. Este tipo de error afecta fundamentalmente a los pronombres que desempeñan funciones oracionales de sujeto y de CI; es, sin embargo, muy similar el principio que los estudiantes deben manejar para resolver anáforas con otros procedimientos (por ejemplo, la repetición léxica o la alternancia forma plena/pronombre).

En este mismo terreno de la anáfora textual, otro conjunto de errores atiende a determinadas características gramaticales que están asociadas con algunas de las piezas léxicas empleadas. Por ejemplo, algunos estudiantes reanalizan como CD ciertos CI; en otras ocasiones, muestran desconocer las restricciones argumentales de algunos predicados, o parecen sentir la necesidad de explicitar complementos locativos o temporales que en español deben quedar sobreentendidos.

Junto a estos errores de referencia al cotexto, hallamos otro gran conjunto de errores en los que el señalamiento se dirige hacia el contexto cognitivo. En tales casos, los elementos anafóricos no remiten ni al contexto lingüístico ni al extralingüístico o empírico, sino a un saber compartido, presente en la conciencia -no en el texto ni en el entorno espacio-temporal inmediato- de los interlocutores. Este tipo de referencia al contexto cognitivo (deixis cognitiva) plantea muchos problemas a los estudiantes, tanto relacionados con el cálculo de ese saber compartido como con el tipo de unidad lingüística que deben escoger para realizar la referencia. El español, en general, usa en estos casos proformas de 2..$^{\mathrm{a}}$ persona, frente a las de $1 .^{\mathrm{a}}$ persona con que suele realizarse la mención al cotexto. Los escritos que analizamos, en cambio, tienden a esta última solución, señalando al elemento aparecido anteriormente en el texto en vez de a la realidad recreada en la mente de emisor y destinatario que se produce por el conocimiento activado en el discurso. 
De la identificación de estos problemas en el uso de las anáforas en producciones escritas de ELE se derivan dos implicaciones relevantes, una de tipo descriptivo y otra de carácter aplicado, estrechamente interrelacionadas. Desde un punto de vista descriptivo, el análisis realizado evidencia que los conocimientos que debe manejar el usuario de español para dominar los mecanismos anafóricos son complejos: tienen que ver con el dominio del paradigma gramatical de unidades lingüísticas con función anafórica pero también con la gestión de la información en el discurso, en particular con la estructura tema-rema y con la función de contraste, y de igual manera con la forma como el español representa cognitivamente cada entidad referida. Esta complejidad implica describir la anáfora desde todas estas perspectivas: la gramatical, la informativa y la cognitiva. Además, el estudiante extranjero debe poseer cierto conocimiento léxico sobre los verbos que exigen complementación semántica para saber qué argumentos han de ser recuperados anafóricamente de forma expresa.

Desde un punto de vista didáctico, es necesario que la compleja descripción del funcionamiento de la anáfora sea trasladada a los materiales y actividades de ELE. Una gramática pedagógica debe nutrirse precisamente de datos reales sobre los principales problemas que plantea el uso del español a quienes lo están aprendiendo. En el estudio que hemos presentado se aportan ejemplos de las áreas en las que conviene incidir en la enseñanza-aprendizaje del ELE en cuanto al mecanismo referencial de la anáfora. A partir de aquí, se hace patente la necesidad de ofrecer a los estudiantes de ELE muestras contextualizadas y claras del funcionamiento anafórico de las distintas unidades lingüísticas implicadas.

\section{REFERENCIAS BIBLIOGRÁFICAS}

Bachman, L. (1990): Fundamental considerations in language testing, Oxford, Oxford University Press (trad. esp. del capítulo 4: «Habilidad lingüística comunicativa», en Llobera, M. et al., Competencia comunicativa. Documentos básicos en la enseñanza de lenguas extranjeras, Madrid, Edelsa, 1995, pp. 105-129).

Benveniste, É. (1974): Problèmes de linguistique générale, vol. II, París, Gallimard (trad. esp.: Problemas de lingüistica general, vol. II, México, Siglo XXI, 1977).

BüHLER, K. (1934): Sprachtheorie, Stuttgart, Gustav Fischer (trad. esp.: Teoría del lenguaje, Madrid, Alianza, 1979).

Castañeda Castro, A. (2004): «Potencial pedagógico de la Gramática Cognitiva. Pautas para la elaboración de una gramática pedagógica de español/LE», RedELE, O (Consultable en línea en <http://www.mepsyd.es/redele/revista/ castaneda.shtml $>$ ).

Cifuentes Honrubia, J. L. (1989): Lengua y espacio. Introducción al problema de la deíxis en español, Alicante, Universidad de Alicante.

Conca, M.; Costa, A.; CuencA, M. J. y Lluch, G. (1998): Text i gramàtica. Teoria $i$ pràctica de la competència discursiva, Barcelona, Teide. 
CORDER, S. P. (1967): «The significance of learners' errors», en Error analysis and interlanguage, Oxford, Oxford University Press, pp. 161-170.

Coseriu, E. (1962): Teoría del lenguaje y lingüistica general. Cinco estudios, 3..$^{\mathrm{a}}$ ed., Madrid, Gredos.

DE Kock, J. (dir.) (1990): Gramática española: enseñanza e investigación, Salamanca, Ediciones Universidad de Salamanca.

Demonte, V. (1995): «Dative alternation in Spanish», Probus 7, pp. 5-30.

EGUREN, L. J. (1999): «Pronombres y adverbios demostrativos. Las relaciones deícticas», en Bosque, I. y Demonte, V. (dirs.), Gramática descriptiva de la lengua española, Madrid, Espasa-Calpe, pp. 929-972.

FERNÁNDEZ RAMíREZ, S. (1985-1987): Gramática española, 2.a edición reelaborada, Volumen 3, 2, Madrid, Arco/Libros.

FERnÁNDEZ SORIANO, O. (1999): «El pronombre personal. Formas y distribuciones. Pronombres átonos y tónicos», en Bosque, I. y Demonte, V. (dirs.), Gramática descriptiva de la lengua española, Madrid, Espasa-Calpe, pp. 1209-1273.

Gutiérrez Ordóñez, S. (1999): «Los dativos», en Bosque, I. y Demonte, V. (dirs.), Gramática descriptiva de la lengua española, Madrid, Espasa-Calpe, pp. 1855-1930.

Halliday, M. y Hasan, R. (1976): Cohesion in English, Londres, Longman.

Hymes, D. H. (1971): «On communicative competence», en Pride, J. B. y Homes, J. (eds.), Sociolinguistics, Harmondsworth, Penguin (trad. esp.: «Acerca de la competencia comunicativa", en Llobera, M. et al., Competencia comunicativa. Documentos básicos en la enseñanza de lenguas extranjeras, Madrid, Edelsa, 1995, pp. 27-47).

LANGACKer, R. W. (1987): Foundations of cognitive grammar. Volume I: Theoretical Prerequisites, Stanford, Stanford University Press.

- (1991): Foundations of cognitive grammar. Volume II: Descriptive Applications, Stanford, Stanford University Press

López GaRCíA, A. (1994-1998): Gramática del español I, II y III, Madrid, Arco/Libros.

LujáN, M. (1999): «Expresión y omisión del pronombre personal», en Bosque, I. y Demonte V. (dirs.), Gramática descriptiva de la lengua española, Madrid, Espasa-Calpe, pp. 1275-1315.

Mederos, H. (1988): Procedimientos de cohesión en el español actual, Tenerife, Publicaciones científicas del Excmo. Cabildo Insular de Tenerife.

Moreno Cabrera, J. A. (2000): Curso universitario de lingüistica general, Madrid, 2. ed. corregida, Síntesis (1. a ed. 1991-1994).

SCHANK, R. y AbELSON, R. (1977): Scripts, plans, goals and understanding, Hillsdale (NJ), Erlbaum (trad. esp.: Guiones, planes, metas y entendimiento, Barcelona, Paidós).

Sperber, D. y Wilson, D. (1986): Relevance. Comunication and cognition, Oxford, Basil Blackwell (trad. esp.: La relevancia. Comunicación y procesos cognitivos, Madrid, Visor, 1994).

VAn Dijk, T. A. (1977): Text and context, Londres, Longman (trad. esp.: Texto y contexto. Semántica y pragmática del discurso, Madrid, Cátedra, 1980).

Vicente Mateu, J. A. (1994): La deixis. Egocentrismo y subjetividad en el lenguaje, Murcia, Universidad de Murcia.

ZubizARRETA, M. L. (1999): «Las funciones informativas: tema y foco», en Bosque, I. y Demonte, V. (dirs.), Gramática descriptiva de la lengua española, Madrid, Espasa-Calpe, pp. 4215-4244. 